Г.В. Худов, С.М. Ковалевський, В.В. Василенко, К.А. Тах’ян

Харківський національний університет Повітряних Сил ім. І. Кожедуба, Харків

\title{
ОПТИМІЗАЦІЯ СУМІСНОГО ДИСКРЕТНОГО ПОШУКУ ТА ВИЯВЛЕННЯ ПОВІТРЯНИХ ОБ'ЄКТІВ В РАДІОЛОКАЦІЙНИХ СИСТЕМАХ
}

\begin{abstract}
Предметом вивчення в статті є задача оптимізаиії сумісного дискретного пошуку та виявлення повітряних об'єктів в радіолокаџійних системах. Метою є рішення задачі оптимізації сумісного дискретного пошуку та виявлення повітряних об'єктів в радіолокаційних системах. Отримані такі результати. Встановлено, що сумісна оптимізація дискретного пошуку та виявлення об'єктів дозволяє зменшити час й, відповідно, знизити енергетичні витрати на виявлення повітряних об'єктів в радіолокаційних системах. Була введена у розгляд поточна дискретна зона огляду, поставлена й вирішена задача знаходження оптимального байєсовського правила прийняття рімення у даній зоні огляду. Сформульовано уточнене оптимальне байєсовське правило прийняття рішення, а саме при рішенні задачі перевірки простої гіпотези проти простої альтернативи сумісна оптимізація дискретного пошуку та виявлення об'єктів зводиться до знаходження рівномірно-оптимальної стратегії пошуку об'єкту у дискретних комірках зони пошуку, обчисленню максимуму безумовного відношення правдоподібності у поточній групі підобластей пошуку та порівнянню його з порогом. Напрямком подальших досліджень є розгляд випадків пошуку та виявлення, коли підобласті зони пошуку мають неоднаковий розмір та коли їх розмір може змінюватися у процесі проведення пошуку та виявлення.
\end{abstract}

Ключові слова: радіолокаційна система, повітряний об'єкт, сумісний дискретний пошук та виявлення, критерій мінімуму середнього ризику, оптимальне байєсовське правило прийняття рішення.

\section{Вступ}

Постановка проблеми у загальному вигляді. На сьогоднішній день цілий клас інформаційних систем використовується для рішення задачі пошуку та виявлення об'єктів в умовах обмеженого пошукового потенціалу [1-5].

Оцінимо можливість зниження вимог до пошукового потенціалу за рахунок сумісної байєсовської оптимізації пошуку та виявлення повітряних об'єктів в радіолокаційних системах. При цьому необхідно зменшити час пошуку та виявлення повітряних об'єктів в радіолокаційних системах за рахунок оптимізації просторово-часового розподілу пошукового потенціалу. Специфіка функціонування радіолокаційної системи у режимі дискретного пошуку при цьому враховується.

Мета статті - рішення задачі оптимізації сумісного дискретного пошуку та виявлення повітряних об'єктів в радіолокаційних системах.

Аналіз останніх досліджень і публікацій. На сьогоднішній день задачі пошуку та виявлення об'єктів в інформаційних системах вирішуються незалежно одна від одної [3-5]. Наведені методи оптимізації [6] розглядають пошук та виявлення як єдину задачу тільки у постановочному плані, а рішення отримані для окремих складових поставленої задачі.
В роботі [7] для випадку безперервного огляду деякої області сформульовано уточнене байєсове правило прийняття рішення про виявлення об'єкту, яке полягає у тому, що при рішенні задачі перевірки простої гіпотези проти простої альтернативи сумісна оптимізація пошуку та виявлення об'єктів зводиться до знаходження рівномірно-оптимальної стратегії пошуку, обчислення максимуму безумовного відношення правдоподібності у поточній зоні огляду та порівняння його з порогом.

Проаналізуємо класичний підхід до вирішення задачі виявлення 3 позиції теорії статистичних рішень [8]. В теорії статистичних рішень при наявності повного комплекту апріорних даних використовується критерій середнього ризику - середнього значення плати за прийняття рішення при перевірці статистичних гіпотез [9]. При цьому, основними характеристиками середнього ризику та його складових елементів $є$ інтегральні характеристики. За допомогою таких характеристик можна отримати деякі показники якості пошуку та виявлення об'єкта у деякій заданій зоні огляду в цілому. Очевидно, що при цьому одним і тим же інтегральним показникам якості будуть задовольняти нескінченна множина стратегій пошуку.

Поширимо результати, які отримані у [7], на випадок рішення задачі дискретного пошуку та виявлення нерухомого одиночного об’єкту. 


\section{Виклад основного матеріалу}

Розглянемо задачу сумісної байєсовської оптимізації дискретного пошуку та виявлення об’єктів. Для цього будемо використовувати критерій мінімуму середнього ризику, а саме середнього значення плати за прийняття рішення про перевірці статистичних гіпотез.

На рис. 1 наведено співвідношення поточної зони огляду $\Omega(t)$ та загальної зони пошуку $\Omega$.

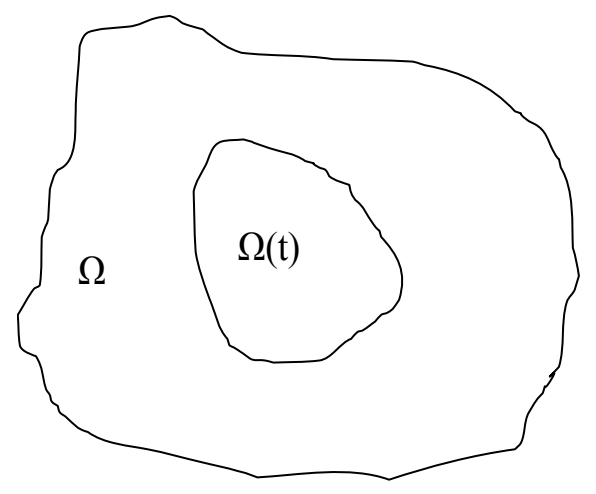

Рис. 1. Співвідношення поточної зони огляду $\Omega(t)$ та загальної зони пошуку $\Omega$

Для подальших досліджень розіб’ємо зону пошуку $\Omega$ на $N$ підобластей $\Omega_{i}$, таких що $\sum_{i=1}^{N} \Omega_{i}=\Omega$. Середнє значення ризику в підобласті $\Omega_{j}$ позначимо як $R_{j}$.

Введемо у розгляд поточну зону огляду $\Omega\left(t_{i}\right)=\sum_{j\left(t_{i}\right)} \Omega_{j}$, де $j-$ номер підобласті пошуку та виявлення об'єкту в момент часу $t$. Індекс $j$ показує порядковий номер підобласті, у якій виконується пошук та виявлення об'єкту в момент часу $t_{i}$.

Поставимо задачу знаходження оптимального байєсовського правила прийняття рішення у поточній дискретній зоні пошуку $\Omega\left(t_{i}\right)$. При такій постановці задачі з'являється додатковий параметр оптимізації: поточні розміри та положення дискретної зони $\Omega\left(t_{i}\right)$ у загальній зоні $\Omega$.

Відповідно, створюються умови для знаходження оптимальної, за байєсовським критерієм мінімуму середнього ризику, стратегії сумісного пошуку та виявлення об'єкта в зоні пошуку дискретної структури.

Рішення такої задачі, як і в теорії пошуку, так і в теорії виявлення раніш біло відсутнє.

Відповідно до [7] середнє значення ризику у поточній зоні пошуку $\Omega\left(t_{i}\right)$ тепер може бути знайдено як:

$$
\begin{aligned}
& R\left(t_{i}\right)=\sum_{\Omega\left(t_{i}\right)} R_{j}=R_{0}-\left(\left(I_{10}-I_{11}\right)\right. \\
& \left.\sum_{\Omega\left(t_{i}\right)} P_{1 j}\left(\gamma_{1}, t_{i}\right)-\left(I_{01}-I_{00}\right) \sum_{\Omega\left(t_{i}\right)} P_{0 j}\left(\gamma_{1}, t_{i}\right)\right),
\end{aligned}
$$

де $P_{1 j}\left(\gamma_{1}, t_{i}\right)$ - поточне значення безумовної ймовірності вірного виявлення об'єкту у $j$-й підобласті на момент часу $t$;

$$
P_{0 j}\left(\gamma_{1}, t_{i}\right) \text { - поточне значення безумовної }
$$
ймовірності помилкової тривоги у $j$-й підобласті на момент часу $t$.

Будемо рахувати, що $R_{0}$ - невід'ємна постійна константа для поточної зони пошуку $\Omega\left(t_{i}\right)$ в момент часу $t$. Баєсовське правило перевірки простої гіпотези $H_{0}$ проти простої альтернативи $H_{1}$ у поточній дискретній зоні $\Omega\left(t_{i}\right)$ зони $\Omega$ запишемо у наступному вигляді:

$$
\frac{\sum_{\Omega\left(t_{i}\right)} P_{1 j}\left(\gamma_{1}, t_{i}\right)}{\sum_{\Omega\left(t_{i}\right)} P_{0 j}\left(\gamma_{1}, t_{i}\right)} \stackrel{\substack{\gamma_{1} \\>}}{\stackrel{\gamma_{0}}{<} \frac{I_{01}-I_{00}}{I_{10}-I_{11}} .}
$$

Переходячи до безумовного відношення правдоподібності

$$
l\left(t_{i}\right)=\frac{\sum_{\Omega\left(t_{i}\right)} P_{1 j}\left(\gamma_{1}, t_{i}\right)}{\sum_{\Omega\left(t_{i}\right)} P_{0 j}\left(\gamma_{1}, t_{i}\right)} .
$$

Вираз (2) запишемо у вигляді:

$$
l\left(t_{i}\right) \underset{\gamma_{0}}{<} \frac{\gamma_{1}}{>} \frac{I_{01}-I_{00}}{I_{10}-I_{11}},
$$

Таким чином, отримане на основі виразів (1) та (2) оптимальне байєсовське правило (3) перевірки простої гіпотези проти простої альтернативи складається в максимізації безумовного відношення правдоподібності $l\left(t_{i}\right)$ у поточній дискретній зоні $\Omega\left(t_{i}\right)$ та порівняння його з порогом (4):

$$
c_{b}=\frac{I_{01}-I_{00}}{I_{10}-I_{11}},
$$

Причому:

- якщо $l(t) \geq c_{b}$, то приймається рішення $\gamma_{1}$, тобто відхиляється гіпотеза $H_{0}$;

- якщо $l(t)<c_{b}$, то приймається рішення $\gamma_{0}$, тобто приймається гіпотеза $H_{0}$.

У відповідності до (2) оптимізація повинна виконуватися за:

- параметрами умовної ймовірності вірного виявлення $P\left(\gamma_{1} / H_{1}, x\right)$ у підобластях $\Omega_{j}$;

- параметрами поточної дискретної зони пошуку $\Omega\left(t_{i}\right)$. 
Розглянемо важливий частковий випадок. Будемо рахувати, що аналогічно критерію НейманаПірсона фіксується на постійному рівні значення безумовної ймовірності хибної тривоги у підобласті $\Omega_{j}$ в момент часу $t-P_{0 j}\left(\gamma_{1}, t_{i}\right)$.

Тоді згідно (2) знаходження максимуму безумовного відношення правдоподібності зводиться до знаходження максимуму безумовної ймовірності вірного виявлення об'єкту у поточній дискретній зоні $\Omega\left(t_{i}\right)$.

Таким чином, для знаходження байєсовського правила прийняття рішення у поточній дискретній зоні $\Omega\left(t_{i}\right)$ загальної зони $\Omega$ поряд 3 рішенням задачі перевірки гіпотез у даній зоні повинна бути вирішена задача знаходження оптимальної, за байєсовським критерієм мінімуму середнього ризику, стратегії пошуку об'єкту. Стратегія пошуку $\lambda\left(\Omega_{j}, t_{i}\right) \epsilon$ правило, яке у будь-який момент часу $t_{\lambda}$ встановлює, у якій підобласті $\Omega_{j}$ зони повинен проводитися пошук та 3 якими енергетичними витратами. Для подальших досліджень введемо основні обмеження на стратегію пошуку, які зазвичай використовуються у теорії пошуку. Будемо вимагати, щоб стратегія пошуку $\lambda\left(\Omega_{j}, t_{i}\right)$ була Турізаною, тобто, $\lambda\left(\Omega_{j}, t_{i}\right)=0$ при $t_{i}>T$ й $x \in \Omega$. Іншими словами, повинна виконуватися умова обов'язкового перегляду зони $\Omega$ за час пошуку $T$.

Очевидно, що:

$$
\begin{aligned}
& \lambda\left(\Omega_{j}, t_{i}\right)>0, \quad \text { для } \quad \Omega_{j} \in \Omega\left(t_{i}\right) ; \\
& \lambda\left(\tilde{\Omega}, t_{i}\right)=0, \quad \text { для } \quad \tilde{\Omega} \in \Omega / \Omega\left(t_{i}\right) .
\end{aligned}
$$

Будемо рахувати, що стратегія пошуку повинна бути постійна для усіх підобластей, які продивляються у фіксований момент часу $t_{i}$. При цьому міра поточної зони $\Omega\left(t_{i}\right)$ складається 3 підобластей $\Omega_{j}$, які переглядаються у момент часу $t_{i}$.

$$
\Omega\left(t_{i}\right)=\sum_{j} \Omega_{j} .
$$

Окрім вказаних вище властивостей стратегії пошуку будемо вимагати, щоб вона задовольняла умові оптимальності, яка полягає у тому, що якщо кожній Т-урізаній стратегії $\lambda\left(\Omega_{j}, t_{i}\right)$ відповідає функціонал $P\left(\lambda\left(\Omega_{j}, t_{i}\right)\right)$, то стратегія $\lambda_{\text {opt }}\left(\Omega_{j}, t_{i}\right)$ буде оптимальною, якщо:

$$
P\left(\lambda_{\text {opt }}\left(\Omega_{j}, t_{i}\right)\right)=\sup P\left(\lambda\left(\Omega_{j}, t_{i}\right)\right),
$$

де $P\left(\lambda\left(\Omega_{j}, t_{i}\right)\right)$ - безумовна ймовірність вірного виявлення об'єкта на момент часу $t_{i}$ при стратегії $\lambda\left(\Omega_{j}, t_{i}\right)$.
Також будемо вимагати, щоб стратегія пошуку була оптимальною для будь-якого моменту часу $T$ закінчення пошуку, тобто у який би момент часу пошук не був би перерваний, аж до цього моменту часу він повинен бути оптимальним за критерієм максимуму безумовної ймовірності вірного виявлення.

3 аналізу результатів за вибором стратегій пошуку, досліджених у теорії пошуку, 3 усіх стратегій найбільш повно умовам (5-7) задовольняє клас рівномірно-оптимальних стратегій пошуку. Стратегія $\lambda\left(\Omega_{j}, t_{i}\right) \quad \epsilon$ рівномірно-оптимальною, якщо іiі будь-яка Т-урізана стратегія оптимальна, тобто

$$
P\left(\lambda\left(\Omega_{j}, t_{i}\right)\right)=P\left(\lambda_{\text {opt }}\left(\Omega_{j}, t_{i}\right)\right), \quad \forall t_{i} \leq T .
$$

Таким чином, при вирішенні задачі знаходження за байєсовським критерієм мінімуму середнього ризику стратегії пошуку та виявлення об'єкту оптимальною $є$ рівномірно-оптимальна стратегія пошуку, у відповідності до якої повинні бути обрані поточні розміри й положення зони $\Omega\left(t_{i}\right)$ у загальній зоні пошуку $\Omega$.

У відповідності до (2) при фіксованому на постійному рівні значенні безумовної ймовірності хибної тривоги оптимізаційна задача буде формулюватися наступним чином:

$$
\begin{gathered}
P_{1}\left(\gamma_{1}, t_{i}\right) \rightarrow \max ; \\
\lambda\left(\Omega_{j}, t_{i}\right) \geq 0, \quad t_{i}>0 ; \\
\sum_{\Omega\left(t_{i}\right)} \lambda\left(\Omega_{j}, t_{i}\right)=L_{0}, \quad t_{i}>0 ; \\
\sum_{j} \lambda\left(\Omega_{j}, t_{i}\right)=\varphi\left(t_{i}\right) ; \\
\sum_{\Omega\left(t_{i}\right)} \varphi\left(t_{i}\right)=L_{0} t_{i},
\end{gathered}
$$

де $P_{1}\left(\gamma_{1}, t_{i}\right)$ - безумовна ймовірність виявлення об'єкта на момент часу $t_{i}$ у дискретній зоні пошуку $\Omega\left(t_{i}\right)$;

$L_{0} \quad$ - характеризує потужність пошукової системи;

$\varphi\left(t_{i}\right)$ - пошукове зусилля у зоні пошуку $\Omega$ на момент часу $t_{i}$.

Рішення оптимізаційної задачі (9) для дискретного випадку отримати достатньо складно. Тому в деякій мірі переформулюємо оптимізаційну задачу (9) й для iіi рішення використаємо відомий підхід.

Основною змінною тепер будемо вважати величину $0 \leq P_{1 j} \leq 1-$ умовну ймовірність того, що об'єкт буде виявлений при перегляді підобласті 3 номером $l$ зони $\Omega_{j}$. Але при умові, що об'єкт 
справді знаходиться в зоні $\Omega_{j}$ й раніш не був виявлений. При цьому мається на увазі, що перегляди 3 номерами $1,2, \ldots, l-1$ підобласті $\Omega_{j}$ проводилися раніш, при чому не обов'язково послідовно, одне за одним.

Введемо позначення $q_{l j}=1-P_{l j}$. Нехай зона $\Omega_{j}$ проглядається $n_{j}$ разів. Тоді умовна ймовірність того, що об’єкт у зоні $\Omega_{j}$ буде виявлений при перегляді з номером $l \in P_{i j} \prod_{i=1}^{l-1} q_{i j}$.

Якщо передивляються усі зони $\Omega_{j}, \quad j=\overline{1, N}$, а зона $\Omega_{j}$ передивляється $n_{j}$ разів, то безумовна ймовірність виявлення об'єкта на протязі цієї послідовності переглядів є:

$$
\sum_{j=1}^{N} P_{j} \sum_{l=1}^{n_{j}} P_{i j} \prod_{i=1}^{l-1} q_{i j}
$$

де $P_{j}-$ апріорна ймовірність розподілу місцеположення об'єкту у зоні $\Omega_{j}$.

$$
\text { Вводячи умову } \sum_{j=1}^{N} n_{j} S_{j} \leq C \text {, }
$$

де $C$ - загальний пошуковий потенціал, виділений за час $T$;

$$
\begin{aligned}
& n_{j} \in Z=\{0,1,2, \ldots\} ; \\
& S_{j} \text { - площа } j \text {-ї підобласті зони пошуку } \Omega .
\end{aligned}
$$

Отримаємо наступну оптимізаційну задачу:

$$
\begin{gathered}
\sum_{j=1}^{N} P_{j} \sum_{l=1}^{n_{j}} P_{i j} \prod_{i=1}^{l-1} q_{i j} \rightarrow \max ; \\
\sum_{j=1}^{N} n_{j} S_{j} \leq C ; \\
n_{j} \in Z, \quad j=\overline{1, N} .
\end{gathered}
$$

У оптимізаційній задачі (11) мається два види невідомих величин:

- пошукові зусилля, які виражені цілими числами $n_{1}, n_{2}, \ldots, n_{k}$;

- зони $\Omega_{1}, \Omega_{2}, \ldots, \Omega_{N}$.

Перепишемо оптимізаційну задачу (11) у вигляді задачі динамічного програмування [10-11]:

$$
\begin{gathered}
f_{N}(\mathrm{z})=\max _{n_{j}, j=1, N}\left\{\sum_{j=1}^{N} P_{j} \sum_{l=1}^{n_{j}} P_{i j} \prod_{i=1}^{l-1} q_{i j}\right\}, \\
\text { де } \quad \sum_{j=1}^{N} n_{j} S_{j} \leq z .
\end{gathered}
$$

Вирішуючи

(12) 3

оптимізаційної теореми Белмана [6; 12], отримаємо оптимальне число переглядів кожної зони. Після знаходження оптимального числа переглядів кожної зони визначимо порядок переглядів цих зон. При цьому введемо умову забезпечення мінімального часу пошуку й виявлення об'єкту. Для цього будемо використовувати відношення Блекуела-БлекаКадана:

$$
\frac{P_{j} P\left(\gamma_{1} / H_{1}, i, j\right) \prod_{l=1}^{i-1} \bar{P}\left(\gamma_{1} / H_{1}, l, j\right)}{S_{j}},
$$

де $P\left(\gamma_{1} / H_{1}, i, j\right)=1-\bar{P}\left(\gamma_{1} / H_{1}, i, j\right)$;

$i$ - число переглядів $j$-ї зони, $i=\overline{1, u_{i-1}^{o p t}}$;

$j=\overline{1, k}, k$ - загальне число зон у зоні пошуку $\Omega$.

Упорядкувавши відношення (13) у порядку спадання, вирішувати задачу пошуку й виявлення необхідно у тому ж порядку.

На основі виконаних досліджень можна сформулювати наступне уточнене оптимальне байєсовське правило прийняття рішення: при рішенні задачі перевірки простої гіпотези проти простої альтернативи сумісна оптимізація дискретного пошуку та виявлення об'єктів зводиться до:

- знаходження рівномірно-оптимальної стратегії пошуку;

- обчисленню максимуму безумовного відношення правдоподібності у поточній дискретній зоні $\Omega\left(t_{i}\right)$;

- порівнянню його $з$ порогом.

При виконанні вказаного правилу середній час до виявлення об'єкту може бути обчислений за формулою (14):

$$
T_{m}=\int_{0}^{T} Q(t) d t
$$

де $Q(t)$ - безумовна ймовірність невиявлення об'єкту.

3 урахуванням того, що $Q(t)=1-P_{1}\left(\gamma_{1}, t\right)$ для дискретного пошуку та виявлення запишемо (15):

$$
T_{m}=\sum_{j}\left(1-P_{j} P_{1}\left(t_{j}\right)\right) \Delta t_{j}
$$

де $P_{1}\left(t_{j}\right)$ - умовна ймовірність виявлення об’єктів у підобласті $\Omega_{j}$;

$$
\Delta t_{j} \text { - час, відведений на перегляд підобласті }
$$
$\Omega_{j} ;$

$\sum_{j} \Delta t_{j}=T$

Для кількісних оцінок будемо вважати, що $P_{j}=P_{1}\left(t_{j}\right), \Delta t_{j}=\Delta t$. 
Розглянемо два часткових випадки:

I. $P_{1}=P_{2}=0,5 ; \Delta t=0,5 T$.

II. $P_{1}=0,7 ; P_{2}=0,3 ; \Delta t=0,5 T$.

Для даних випадків отримаємо:

I. $T_{\text {cep }} \approx 0,75 T$.

II. $T_{\text {cep }} \approx 0,71 T$.

Можна побачити, що при сумісній оптимізації пошуку та виявлення забезпечується виграш у середньому часі до виявлення повітряного об’єкту.

\section{Висновки}

Таким чином, можна стверджувати, що сумісна оптимізація дискретного пошуку та виявлення об'єктів дозволяє зменшити час й, відповідно, знизити енергетичні витрати на виявлення повітряних об'єктів в радіолокаційних системах.
Була введена у розгляд поточна дискретна зона огляду, поставлена й вирішена задача знаходження оптимального баєсовського правила прийняття рішення у даній зоні огляду.

Сформульовано уточнене оптимальне баєсовське правило прийняття рішення, а саме при рішенні задачі перевірки простої гіпотези проти простої альтернативи сумісна оптимізація дискретного пошуку та виявлення об'єктів зводиться до знаходження рівномірно-оптимальної стратегії пошуку об'єкту у дискретних комірках зони пошуку, обчисленню максимуму безумовного відношення правдоподібності у поточній групі підобластей пошуку та порівнянню його з порогом.

Напрямком подальших досліджень $є$ розгляд випадків пошуку та виявлення, коли підобласті зони пошуку мають неоднаковий розмір й коли їх розмір може змінятися у процесі проведення пошуку та виявлення.

\section{Список літератури}

1. Rich feature hierarchies for accurate object detection and semantic segmentation / R.B. Girshick, J. Donahue, T. Darrell, J. Malik // IEEE CVPR. - 2014. - P. 580-587.

2. Подъездков Ю.А. Космическая съемка Земли. Космическая радиолокационная съемка поверхности Земли. Справочно-аналитическое издание / Ю.А. Подъездков. - М.: Радиотехника, 2004. - 66 с.

3. Верба В.С. Радиолокационные системы землеобзора космического базирования / В.С. Верба. - М.: Радиотехника, 2010. $-680 \mathrm{c}$.

4. Wickens T.D. Elementary signal detection theory / T.D. Wickens. - New York: Oxford University Press, $2002 .-277$ p.

5. Nam Y. Intelligent video surveillance system / Y. Nam, S. Rho, J.H. Park // Multimedia Tools and Applications. March, 2012. - Vol. 57(2). - P. 315-334. https://doi.org/10.1007/s11042-010-0677-x.

6. Хеллман О. Введение в теорию оптимального поиска / О. Хеллман. - М.: Наука, 1985. - 246 с.

7. The Bayes Rule of Decision Making in Joint Optimization of Search and Detection of Objects in Technical Systems / H. Khudov, I. Khizhnyak, F. Zots, G. Misiyuk, O. Serdiuk // IJETER. - 2020. - № $\quad 8(1), \quad$ P. $\quad 7-12$. https://doi.org/10.30534/ijeter/2020/02812020.

8. Method for the detection of smallsized air objects by observational radars / H. Khudov, A. Zvonko, S. Kovalevskyi, V. Lishchenko, F. Zots // Eastern-European Journal of Enterprise Technologies. - 2018. - № 2(92). - P. 61-68. https://doi.org/10.15587/1729-4061.2018.126509.

9. The Method of Increasing the Detection Range of Unmanned Aerial Vehicles In Multiradar Systems Based on Surveillance Radars / V. Lishchenko, H. Khudov, V. Tiutiunnyk, V. Kuprii, F. Zots, G. Misiyuk // 2019 IEEE 39th International Conference on Electronics and Nanotechnology (ELNANO). - Kyiv, 16-18 April 2019. - P. 559-562. https://doi.org/10.1109/ELNANO.2019.8783263.

10. Barniv Y. Dynamic programming solution for detecting dim moving targets / Y. Barniv // IEEE Transactions on Aerospace and Electronic Systems. - January 1985. - Vol. AES-21, Iss. 1, P. 144-156. https://doi.org/10.1109/TAES.1985.310548.

11. Окулов С.М. Динамическое программирование / С.М. Окулов, О.А. Пестов. - М.: Бином, 2016. -245 с.

12. Бех О.В. Математичне програмування: Навчальний посібник / О.В. Бех, Т.А. Городня, А.Ф. Щербак. - Львів: Магнолія, 2007. - 200 c.

\section{References}

1. Girshick, R.B., Donahue, J., Darrell, T. and Malik, J. (2014), Rich feature hierarchies for accurate object detection and semantic segmentation, IEEE CVPR, pp. 580-587.

2. Podezdkova, Yu.A. (2004), "Kosmicheskaya semka Zemli. Kosmicheskaya radiolokacionnaya semka poverhnosti Zemli. Spravochno-analiticheskoe izdanie" [Space imagery of the Earth. Space radar imaging of the Earth's surface. Reference and analytical publication], Radiotekhnika, Moscow, $66 \mathrm{p}$.

3. Verby, V.S. (2010), “Radiolokacionnye sistemy zemleobzora kosmicheskogo bazirovaniya” [Space Based Radar Surveillance Systems], Radiotekhnika, Moscow, $680 \mathrm{p}$.

4. Wickens, T.D. (2002), Elementary signal detection theory, Oxford University Press, New York, $277 \mathrm{p}$

5. Nam, Y., Rho, S., and Park, J.H. (2012), Intelligent video surveillance system, Multimedia Tools and Applications, No. 57(2), pp. 315-334, https://doi.org/10.1007/s11042-010-0677-x. 
6. Hellman, O. (1985), "Vvedenie v teoriyu optimalnogo poiska" [Introduction to Optimal Search Theory], Nauka, Moscow, $246 \mathrm{p}$.

7. Khudov, H., Khizhnyak, I., Zots, F., Misiyuk, G. and Serdiuk, O. (2020), The Bayes Rule of Decision Making in Joint Optimization of Search and Detection of Objects in Technical Systems, IJETER, No. 8(1), pp. 7-12, https://doi.org/10.30534/ijeter/2020/02812020.

8. Khudov, H., Zvonko, A., Kovalevskyi, S., Lishchenko, V. and Zots, F. (2018), Method for the detection of smallsized air objects by observational radars, Eastern-European Journal of Enterprise Technologies, No. 2(92), pp. 61-68, https://doi.org/10.15587/1729-4061.2018.126509.

9. Lishchenko, V., Khudov, H., Tiutiunnyk, V., Kuprii, V., Zots, F. and Misiyuk, G. (2019), The Method of Increasing the Detection Range of Unmanned Aerial Vehicles In Multiradar Systems Based on Surveillance Radars, IEEE 39th International Conference on Electronics and Nanotechnology (ELNANO), 16-18 April, Kyiv, Ukraine, pp. 559-562. https://doi.org/10.1109/ELNANO.2019.8783263.

10. Barniv, Y. (1985), Dynamic programming solution for detecting dim moving targets, IEEE Transactions on Aerospace and Electronic Systems, January 1985, Vol. AES-21, Iss. 1, pp. 144-156, https://doi.org/10.1109/TAES.1985.310548.

11. Okulov, S.M. and Pestov, O.A. (2016), "Dinamicheskoe programmirovanie" [Dynamic programming], Binom, Moscow, 245 p.

12. Bekh, O.V., Horodnia, T.A. and Shcherbak, A.F. (2007), "Matematychne prohramuvannia" [Mathematical Programming], Mahnoliia, Lviv, 200 p.

\section{Відомості про авторів:}

Худов Геннадій Володимирович доктор технічних наук професор начальник кафедри Харківського національного університету Повітряних Сил ім. І. Кожедуба, Харків, Україна https://orcid.org/0000-0002-3311-2848

\section{Ковалевський Сергій Миколайович} кандидат технічних наук начальник факультету

Харківського національного університету

Повітряних Сил ім. І. Кожедуба,

Харків, Україна

https://orcid.org/0000-0002-1350-9338

\section{Василенко Віталій Віталійович} старший викладач

Харківського національного університету

Повітряних Сил ім. І. Кожедуба,

Харків, Україна

https://orcid.org/0000-0002-3577-7421

Тах'ян Крістіна Альбертівна

науковий співробітник

Харківського національного університету

Повітряних Сил ім. І. Кожедуба,

Харків, Україна

https://orcid.org/0000-0003-0087-9601
Information about the authors:

Hennadii Khudov

Doctor of Technical Sciences Professor

Head of Department of Ivan Kozhedub Kharkiv

National Air Force University,

Kharkiv, Ukraine

https://orcid.org/0000-0002-3311-2848

Sergiy Kovalevskiy

Candidate of Technical Sciences

Chief of Faculty

of Ivan Kozhedub Kharkiv

National Air Force University,

Kharkiv, Ukraine

https://orcid.org/0000-0002-1350-9338

Vitalii Vasylenko

Senior Instructor

of Ivan Kozhedub Kharkiv

National Air Force University,

Kharkiv, Ukraine

https://orcid.org/0000-0002-3577-7421

Kristina Tahyan

Research Associate

of Ivan Kozhedub Kharkiv

National Air Force University,

Kharkiv, Ukraine

https://orcid.org/0000-0003-0087-9601

\title{
ОПТИМИЗАЦИЯ СОВМЕСТНОГО ДИСКРЕТНОГО ПОИСКА И ОБНАРУЖЕНИЯ ВОЗДУШНЫХ ОБЪЕКТОВ В РАДИОЛОКАЦИОННЫХ СИСТЕМАХ
}

\author{
Г.В. Худов, С.Н. Ковалевский, В.В. Василенко, К.А. Тахьян
}

Предметом изучения в статье является задача оптимизации совместного дискретного поиска и обнаружения воздушных объектов в радиолокационных системах. Целью является решение задачи оптимизации совместного дискретного поиска и обнаружения воздушных объектов в радиолокационных системах. Получены следующие результаты. Установлено, что совместная оптимизация дискретного поиска и обнаружения объектов позволяет уменьшить время u, соответственно, снизить энергетические затраты на выявление воздушных объектов в радиолокационных системах. Была введена в рассмотрение текущая дискретная зона обзора, поставлена и решена задача нахождения оптимального байесовского правила принятия решения в данной зоне обзора. Сформулировано уточненное оптимальное байесовское правило принятия решения, а именно, при решении задачи проверки простой гипотезы против простой 
альтернативы совместная оптимизация дискретного поиска и обнаружения объектов сводится к нахождению равномерно-оптимальной стратегии поиска объекта в дискретных ячейках зоны поиска, вычислению максимума безусловного отношения правдоподобия в текущей группе подобластей поиска и сравнению его с порогом. Направлением дальнейиих исследований является рассмотрение случаев поиска и обнаружения, когда подобласть зоны поиска имеют неодинаковый размер и когда их размер может изменяться в прочессе проведения поиска и обнаружения.

Ключевые слова: радиолокационная система, воздушный объект, совместный дискретный поиск и обнаружение, критерий минимума среднего риска, оптимальное байесовское правило принятия решения.

\section{OPTIMIZATION OF JOINT DISCRETE SEARCH AND DETECTION OF AIR OBJECTS IN RADAR SYSTEMS}

H. Khudov, S. Kovalevskiy, V. Vasylenko, K. Tahyan

The subject of this article is the optimization of joint discrete search and detection of airborne objects in radar systems. The goal is to solve the problem of optimizing joint discrete search and detection of airborne objects in radar systems. The following results are obtained. It has been established that the joint optimization of discrete search and detection of objects makes it possible to reduce the time and, accordingly, reduce the energy costs of identifying air objects in radar systems. The current discrete field of view was introduced, the task of finding the optimal Bayes decision rule in this area of view was posed and solved. The refined optimal Bayesian decision-making rule is formulated, which consists of three stages. Namely, when solving the problem of testing a simple hypothesis versus a simple alternative, the joint optimization of discrete search and object detection is reduced to finding a uniformly optimal strategy for finding an object in discrete cells of the search area at the first stage. The calculation of the maximum unconditional likelihood ratio in the current group of search subdomains in the second stage. And comparing it with the threshold at the final. The direction of further research is to consider cases of search and detection, when the area of the search area is not the same size and when their size can change during the search and detection.

Keywords: radar system, air object, joint discrete search and detection, minimum average risk criterion, optimal Bayes decision rule. 